\title{
Social Composition, Social Conflict, and Economic Development
}

\author{
Holger Strulik* \\ Leibniz Universität Hannover, Discussion Paper No. 350 \\ ISSN 0949-9962
}

October 2006

This article shows within a simple growth model how the make up of society affects economic performance when property rights are unenforceable. It investigates behavior of non-cooperative social groups that consume, produce, and appropriate resources either peacefully or through contest. For the case of symmetric groups it is shown that economic growth is generated only in peaceful societies. For the case of asymmetric groups rebel-equilibria are investigated in which a large majority behaves peacefully although challenged by an aggressive minority. In each case it is shown how the possibility of conflict and its intensity and the rate of economic growth depend on social fractionalizaton, general productivity of the economy, and the ease at which resources are appropriated. A final part extends the analysis towards behavior of non-benevolent social elites.

Keywords: Social Conflict, Social Fractionalization, Property Rights, Stagnation, Growth JEL Classification: C73, D74, O11

\footnotetext{
*Department of Economics, University of Hannover, Koenigsworther Platz 1, 30167 Hannover, Germany, email: strulik@vwl.uni-hannover.de. I would like to thank Ines Lindner, Oded Galor, Nikolaus Siegfried, participants of research seminars at Hamburg, Groningen, Muenster, and Zuerich Universities, Hebrew University, at EPRU, Copenhagen, and participants of the Annual Conferences of the German Economic Association and of the European Economic Association for useful comments.
} 


\section{INTRODUCTION}

This article investigates how the make up of society affects the economy when property rights are unenforceable. For that purpose we take a simple model of economic growth and explore in a unifying framework two possibilities to acquire resources: peaceful appropriation and violent contest. Depending on the mode of resource appropriation the economy suffers from unenforceable property rights through either one or two channels. The first channel is created through the disincentive to invest. It is always operative irrespective of whether appropriation is peaceful or violent. The second channel is created through the effort that individuals spend on appropriation contest, i.e. the effort lost for productive activities. The main goal of the article is to show how social composition determines these modes of resource appropriation and how appropriative behavior feeds back through the investment- and conflict-channel on long- run economic growth.

When property rights on individual capital are not enforceable, economy-wide capital constitutes in fact a common pool resource and investors play a dynamic common pool game. They know that a part of the returns on their investment will be appropriated by other members of society and this knowledge drives down the incentive to invest and reduces the growth rate of the macro-economy. The common pool framework leaves open how resources are appropriated. Appropriation may happen peacefully in the sense that members of society are not engaged in a costly contest about the economy's resources. One strand of literature related to this article investigates investment and growth when such a peaceful society is given by assumption. ${ }^{1}$ On the other hand appropriation can be through contest. In this case the share of appropriated resources depends on the expenditure of time or material spend on appropriative activities (usually called fighting) relative to the expenditure of other members in society. A second strand of literature related to this article investigates economic consequences when such violent appropriation is given by assumption. ${ }^{2}$

In this article we treat the mode of appropriation as a choice variable. A cross-country inspection of socio-economic histories shows that unenforceable property rights or, more generally, bad institutions are always an impediment to economic development but only some countries at some times suffer additionally from civil conflict. Moreover we frequently observe that only a

\footnotetext{
${ }^{1}$ The basic article is Lane and Tornell (1996). Generalization and extensions are provided by Tornell and Lane (1998), Lindner and Strulik (2004) and Long and Sorger (2006). Benhabib and Rustichini (1996) introduce cooperative appropriation norms in this framework. Lindner and Strulik (2006) investigate how these norms are affected by social fractionalization.

${ }^{2}$ There exists a large literature on conflict in static environments based on Hirshleifer (1988). Dynamic models of conflict are investigated by Garfinkel (1992), Grossman and Kim (1996), McDermott (1997), and Gonzalez (2006). Some models allow for peaceful behavior but this is then only observed in situations when private property exists and is secure, i.e. not challenged by others.
} 
subset of society (the rebels, the guerilla) engages in conflict while others behave peacefully.

In order to investigate how investment and conflict are affected by social diversity we subdivide society into several groups. Possible intra-group conflict is assumed to be completely resolved so that members of a group cooperate with each other and compete with members of other groups. Ever since Sherif et al.'s (1961) famous Robber's Cave experiment it has been widely verified in social psychology that groups form up and conflict between groups arises as a result of conflicting interests (see, for example, Baron and Byrne, 2004). Here, conflict of interest exist because property rights are not defined or unenforceable.

According to Tajfel and Turner (1979) our strive for a satisfactory social identity and higher self-esteem leads us to the distinction between groups and the emphasis of the desirability of the in-group. The classic example for in-group favoritism and out-group discrimination is ethnocentrism (LeVine and Campbell, 1972). It it argued that groups form along ethnic lines because if one belongs to a group of low status, a reasonable strategy could be to switch to another group. The use of ethnic markers - in particular when they are connected with visible features - makes such a change more difficult. This renders ethnic groups more infiltration proof and cohesion and cooperation within the group can be sustained more easily. Here, we will speak nevertheless most of the time of social groups in order to keep the theoretical results more general and only interpret these groups as ethnic when we compare results with the empirical evidence because the existing econometric studies that take social composition into acount are mostly about the association of economic performance and ethnic diversity.

Results derived in this article can be confronted with the following evidence. Easterly and Levine (1997) show that ethnically fragmented countries grow less and that this factor is a major determinant of Africa's poor growth performance. This finding is confirmed with new data sets by Alesina et al. (2003) and Alesina and La Ferrara (2005). The later study also finds that fractionalization has more negative effects at low income levels. Rodrik (1999) shows that ethnically divided nations react more adversely to external shocks. Easterly (2001a) finds that lower ethnic divisions (and the share of income of the middle class) are associated with higher income and growth, as well as with less civil war, better infrastructure and several other development indicators. Alexander and Harding (2005) show that size of the largest ethnic group is a significant determinant of civil war (along with the export share of primary commodities) while income and education become insignificant once historical institutions are controlled for.

Negative effects of the risk of expropriation and other indicators of bad institutions on economic performance have been shown by Keefer and Knack (1995, 1997), Mauro (1995), and 
Hall and Jones, (1999). Recently, the literature has emphasized an indirect effect of geography on growth through institutional change at colonial times (Acemoglu et al., 2001, Easterly and Levine, 2003, and Rodrik et al., 2004). The implied fact that institutions prevail over centuries and are rarely destroyed or created rapidly helps to justify the simplifying assumption of taking the unenforceability of property rights as given. Using an interaction term Easterly (2001b) finds that the presence of good institutions significantly mitigates the negative effect of ethnic diversity and that the marginal effect of ethnic fractionalization on economic growth as well as on civil war is zero at the maximum level of institutional quality.

Some resources are more easily appropriated than others and their presence may induce more conflict. Collier and Hoeffler (2004) find that the extent of primary commodity exports is the largest single influence on the risk of conflict. Mehlum et al. (2006) find that more natural resources reduce aggregate income under grabber friendly institutions and raise income otherwise. An indirect effect of a country's resource endowment on economic performance through the mode of appropriation is found by Isham et al. (2005). They demonstrate that the relative abundance of point source natural resources and of cocoa and coffee affects the rule of law, political stability, and violence negatively and through this channel indirectly economic growth.

Social groups may differ in number and size. To keep the analysis tractable the paper investigates both criteria separately. In particular the article is organized as follows. The next section sets up a dynamic model of conflict for a society of groups of equal size. Section 3 shows that only peaceful economies grow. If peace prevails, absent property rights still affect growth negatively through the investment channel and we investigate the role of social fractionalization in this context. Section 4 derives conditions for conflict to occur and investigates how appropriation opportunities and social fractionalization affect conflict intensity.

From Section 5 onward the analysis is focussed on two groups of different size. This allows to abandon the symmetry assumption. First we derive conditions for growth and conflict when groups behave qualitatively similar in the sense that both decide for or against investment and conflict. We show that the previously derived no-peace-no-growth result remains valid as long as both groups engage in appropriation contest. Asymmetric societies can also display qualitatively different group behavior. Section 6 discusses rebel-equilibria where the majority of society behaves peacefully and is challenged by a predatory minority. In Section 7 groups are endowed with different inherent (political) power. Equilibria of predatory social elites and mass resistance are investigated. Section 8 concludes by mentioning limitations of the current approach and possible extensions for future research. 


\section{Investment and Appropriation in a Symmetric Society}

Consider an economy populated by $n \geq 2$ groups of equal size. Total population is normalized to one to facilitate comparison with the standard growth model. Hence, each group $i, i=1,2, \ldots, n$, consists of a continuum $[0,1 / n]$ of persons. Conflict within groups has been completely resolved so that each group acts as one man. Every group is endowed with one unit of time of which it may decide to devote a part $\tau_{i}$ on an appropriation contest with other groups. In line with the conflict literature we call this activity fighting. It could be alternatively called rent-seeking, robbery, looting, or civil war. The crucial feature is that the time devoted to contest cannot be used for production of goods anymore. The induced loss of production constitutes the opportunity cost of an engagement in conflict. We call a group that decides to spend no time on appropriation contest $\left(\tau_{i}=0\right)$ peaceful and a society that consists exclusively of peaceful groups a peaceful society.

Economy-wide capital is denoted by $k$ and disposable capital of group $i$ by $k_{i}$. A group's share of capital depends on its appropriation activities relative to total appropriation activity of all contestants.

$$
\frac{k_{i}}{k}=\frac{\alpha+\tau_{i}}{n \alpha+\sum_{j=1}^{n} \tau_{j}}, \quad \alpha>0 .
$$

The positive parameter $\alpha$ distinguishes the appropriation contest from most of the conflict literature. Without $\alpha$, a non-fighting group would receive nothing if one or more other groups are fighting. In other words, in an equilibrium of peace any group could appropriate the entire capital stock by an infinitesimal small fighting activity. This feature would make long-run peace unstable. A positive $\alpha$ avoids that social conflict is already imposed by assumption and allows to derive conditions for peace and conflict as equilibrium outcomes. ${ }^{3}$

The magnitude of the parameter $\alpha$ also identifies the kind of capital or resource a society is competing for. Given behavior of the competitors each group's marginal return on fighting is decreasing in $\alpha$ implying that the lower $\alpha$ the higher the share that a group can appropriate with a certain fighting effort. This way, a high value of $\alpha$ models contest over hardly appropriable resources as, for example, human capital. A low value, on the other hand, indicates comparatively easily appropriated resources as, for example, arable land, cattle, or forests.

Secondly, a group's marginal return on fighting is increasing in the number of groups. This feature reflects the fact that with rising $n$ there are less in-group members to share resources

\footnotetext{
${ }^{3}$ Most of the results can be also obtained with a more general contest success function as used, for example, in Hirshleifer $(1988,1995)$. Konrad $(2002)$ provides an alternative way to rationalize the parameter $\alpha$ as the headstart advantage of investors in a contest with appropriators.
} 
cooperatively with and more out-group members to fight with. The interplay of the effects from social diversity $(n)$ and the ease of resource appropriation $(\alpha)$ will play a dominant role in the subsequent analysis.

Capital is used together with working time to produce output using a function $f\left(\tau_{i}, k_{i}\right)=$ $\left(1-\tau_{i}\right) A k_{i}$, i.e. group $i$ produces $A k_{i}$ units of output in every unit of time that their members do not devote to fighting. Output can be used for consumption or investment. With per capita consumption and investment denoted by $c_{i}$ and $e_{i}$ a group $i$ consumes $c_{i} / n$ units of output and invests $e_{i} / n$ units. Its budget constraint reads

$$
\left(1-\tau_{i}\right) A k_{i}=\left(c_{i}+e_{i}\right) / n
$$

Insert (1) into (2) to see that in a peaceful society $\left(\tau_{i}=0\right.$ for all $\left.i\right)$ every group produces the same income $A k / n$ and everyone receives an income $A k$, which can be used for consumption and investment. So far an economy in peace would be equivalent to the textbook $A k$ growth model. Yet, property rights are not enforceable and all that is a priori known about investment is that it augments the aggregate capital stock.

$$
\dot{k}=\sum_{i=1}^{n} e_{i} / n .
$$

Groups determine consumption and fighting activity in order to maximize intertemporal utility from consumption of their representative member according to $\int_{0}^{\infty} U\left(c_{i}\right) \mathrm{e}^{-\rho t} \mathrm{~d} t$, where $\rho>0$ denotes the time preference rate. Instantaneous utility is of the iso-elastic form, $U\left(c_{i}\right)=\left(c_{i}^{1-\theta}-\right.$ $1) /(1-\theta)$. The analysis focuses on the case where $\theta \geq 1$, which is, however, not restrictive given the empirical evidence on the magnitude of the intertemporal elasticity of substitution (see e.g. Ogaki et al., 1996) .

Taking constraints $(1)-(3)$ and a non-negativity constraint for investment, $e_{i} \geq 0$, into account, the optimization problem for group $i, i=1, \ldots, n$, reads

$$
\begin{aligned}
\max _{\tau_{i}, c_{i}} L_{i} & =\frac{c_{i}^{1-\theta}-1}{1-\theta}+\lambda_{i}\left\{\left(1-\tau_{i}\right) \frac{\alpha+\tau_{i}}{\alpha n+\sum_{j=1}^{n} \tau_{j}} A k+\sum_{j=1, j \neq i}^{n}\left(1-\tau_{j}\right) \frac{\alpha+\tau_{j}}{\alpha n+\sum_{h=1}^{n} \tau_{h}} A k-\sum_{j=1}^{n} \frac{c_{i}}{n}\right\} \\
& +\mu_{i}\left[\left(1-\tau_{i}\right) \frac{\alpha+\tau_{i}}{\alpha n+\sum_{j=1}^{n} \tau_{j}} A k-\frac{c_{i}}{n}\right] .
\end{aligned}
$$

Group $i$ 's shadow price of aggregate capital is denoted by $\lambda_{i}$, and $\mu_{i}$ is a complementary slack variable that assumes the value of zero if investment of group $i$ is strictly positive.

Consider first the conditions for positive investment, i.e. $e_{i}>0$ and $\mu_{i}=0$. We have the usual 
first order condition for consumption

$$
c_{i}^{-\theta}=\lambda_{i}
$$

Taking into account that fighting time must be non-negative, the first order condition for fighting is $\left(\partial L / \partial \tau_{i}\right) \tau_{i}=0$ and $\partial L / \partial \tau_{i} \leq 0$. Since individuals are identical (except for social affiliation) and groups are of equal size, symmetry applies. Setting $\tau_{i}=\tau_{j}$, for all $i, j$ the derivative simplifies to

$$
\frac{\partial L_{i}}{\partial \tau_{i}}=-\lambda_{i} A k / n
$$

From this we immediately obtain one of the main results.

Theorem 1. In symmetric equilibrium only peaceful societies grow economically.

Proof. Growth necessarily requires investment, which requires $\mu_{i}=0$. Since $c^{-\theta}>0$ for all $c_{i}>0, \lambda_{i}>0$, and, hence, $\partial L_{i} / \partial \tau_{i}<0$. This in turn requires $\tau_{i}=0$ for all groups for the Kuhn-Tucker condition to be fulfilled.

The result is explained as follows. Positive investment implies that consumption is lower than income, i.e. an interior solution for consumption. An optimal interior solution depends on the current state of the system, i.e. the aggregate capital stock, and (possibly) time, $c=c(k, t)$, but not on fighting activities $(\tau)$. The only rationale for fighting could then be that it improves future consumption through investment of the appropriated share. But because property rights cannot be enforced, this investment will simply augment the aggregate capital stock from which it was appropriated. In other words, if investment is worthwhile even under unenforceable property rights, an engagement in conflict is a waste of time. This in turn implies that for fighting to be observed consumption has to be at a corner solution where nobody invests. Note that the result just states that investors will not fight and does not allow the conclusion that stagnation causes conflict. Determinants of conflict will be investigated in Section 4 .

The no-peace-no-growth result is independent from the specific functional forms for utility, production, and contest success. ${ }^{4}$ It depends, however, crucially on the symmetry assumption. Since an investor will never fight, a society of symmetric groups is either made up solely of peaceful investors or solely of non-investors. Considering asymmetric groups (of different size or different inherent power) and abandoning the symmetry assumption allows qualitatively dif-

\footnotetext{
${ }^{4}$ This claim is proven in the Appendix. Any claim of generality is, of course, restricted to the non-cooperative Markov strategies under investigation and to (concave) functional forms for which an interior solution for consumption exists. Different strategies will lead to different equilibria. Trigger strategies, for example, can establish inter-group cooperation and quasi-secure property rights as shown by Benhabib and Rustichini (1996) for the case of two groups. The effect of social composition on the possibility of cooperation is investigated by Lindner and Strulik (2006).
} 
ferent group behavior. In particular it becomes possible that a subset of society consists of peaceful investors and a second subset consists of violent non-investors. These possibilities are investigated from Section 5 onwards.

\section{Peace and Growth with Unenforceable Property Rights}

In order to proceed consumption strategies have to be specified. Open-loop strategies require that groups credibly commit to an infinite consumption path. Given that claims on future capital stocks are unenforceable they are inappropriate. Accordingly, we consider Markovian

(or feedback-) strategies $c(k, t)=c(k(t))$ where consumption is determined by the state of the system given by the aggregate capital stock. For a peaceful society the log-differentiated first order condition for consumption and the costate equation for group $i$ read

$$
\begin{aligned}
& -\theta \frac{\dot{c}_{i}}{c_{i}}=\frac{\dot{\lambda}_{i}}{\lambda_{i}} \\
& \lambda_{i}\left(A-\sum_{j=1, j \neq i}^{n} \frac{c_{j}^{\prime}(k)}{n}\right)=\rho \lambda_{i}-\dot{\lambda}_{i} .
\end{aligned}
$$

The sum term on the left hand side of (8) shows that groups take strategic interaction into account. It distinguishes the solution from the standard $A k$-growth model where property rights are secure. Members of group $i$ (and analogously members of all other groups) know that if they invest more and raise the capital stock $(k)$, members of the other groups consume more. Taking these reactions $c_{j}^{\prime}(k)$ into account, they consume more today and invest less than if property rights were secure. To show this formally, we insert (1) and (2) into (3) and apply symmetry. This provides growth of economy-wide capital in a peaceful society as

$$
\dot{k}=A k-c_{i}
$$

Inserting (7) into (8), applying symmetry, using the fact the $c_{i}^{\prime}(k)=\dot{c}_{i} / \dot{k}$, and inserting (9) determines consumption as

$$
c_{i}^{\prime}(k)=\frac{A-\rho-c_{i}^{\prime}(k)(n-1) / n}{\theta\left[A k-c_{i}(k)\right]} c_{i}(k)
$$

Using the method of undetermined coefficients we obtain the consumption strategy

$$
c_{i}=\frac{\theta n}{\theta n-(n-1)} \varphi k, \quad \varphi \equiv A \frac{\theta-1}{\theta}+\frac{\rho}{\theta}
$$

which applies for all groups $i=1, \ldots, n$. Hence, economy-wide capital, individual consumption, and overall consumption grow at the same rate $g_{c} \equiv \dot{c}_{i} / c_{i}$. Inserting (7) into (8) and substituting 
$c_{i}^{\prime}$ from (11) provides economic growth in a peaceful society without property rights: ${ }^{5}$

$$
g_{c} \equiv \frac{A-n \rho}{\theta n-(n-1)} \text {. }
$$

Now the choice of notation pays off since the results can be compared immediately with results for an $A k$-economy with secure property rights. For the standard $A k$-model we refer to the textbook presentation in Barro and Sala-i-Martin (2004, Ch. 4.1, henceforth BS).

Theorem 2. Consider a linear growth model and a society clustered in symmetric groups. Then individuals in a peaceful society with unenforceable property rights consume a larger part of output (i.e. invest less) and realize a lower rate of economic growth than individuals in an otherwise identical society with secure property rights.

Proof. The representative individual in an economy with secure property rights receives the income $A k$ for sure and consumes $c$. Solving the optimization problem leads to the consumption strategy $c=\varphi k$ (See BS for details on this part). Since $\theta n>\theta n-(n-1)$, inspection of (11) shows that individuals in a peaceful society without property rights consume a larger part of $k$ and hence of output, $A k$. This implies that they invest less.

Inserting consumption under secure property rights into the equation of motion provides the long-run growth rate $(1 / \theta)(A-\rho)$ (See BS for details). Since $n \geq 2$, and $\theta \geq 1>(n-1) / n$, growth without property rights according to $(12)$ is lower. ${ }^{6}$

Inspection of (12) proves the following result with respect to social fractionalization.

Theorem 3. Given unenforceable property rights the rate of economic growth is decreasing in the number of competing groups.

In a largely fractionalized society a higher share of the return on investment is appropriated by members of other groups implying a lower return for the in-group. Consequently, the incentive to invest and thus growth decreases with the degree of fractionalization. The result provides a theoretical foundation for the empirical finding that increasing social fractionalization slows down economic growth as shown by Easterly and Levine (1997) and follow-up studies (see Introduction). Fractionalization, however, is only an impediment to growth if property rights

${ }^{5}$ For sufficiency it can be verified that the function $V(k)=\left(\frac{\theta n}{\theta n-(n-1)} \varphi\right)^{-\theta} /(1-\theta)\left[k^{1-\theta}-k_{0}^{1-\theta}\right]+V\left(k_{0}\right)$ satisfies the Hamilton Jacobi Bellman condition

$$
\rho V(k)=\frac{V^{\prime}(k)^{(\theta-1) / \theta}-1}{1-\theta}+V^{\prime}(k)\left[A k-n V^{\prime}(k)^{-1 / \theta}\right]
$$

such that $S(k)=V(k) \mathrm{e}^{-\rho t}$ constitute a value function for group $i, i=1, \ldots, n$.

${ }^{6}$ Note that $A$ of the current model comprises $(A-\delta)$ in BS and that BS allow for positive population growth (there denoted by $n$ ) which is set to zero for comparison with the current model. Furthermore, $A>\rho$, for a meaningful solution with secure property rights, which is assumed to hold throughout this article. 
are unenforceable. This accords with Easterly's (2001b) finding that growth and civil conflict are uneffected by fractionalization at the highest degree of institutional quality.

Generally, investment requires that the net return is larger than the time preference rate. In the textbook model this implies that capital productivity $A$ has to exceed $\rho, A>\rho$. If property rights are unenforceable, this condition is not sufficient. Inspection of (12) shows that investment and growth requires $A / n>\rho$, i.e. capital productivity divided by the number of groups has to exceed the time preference rate. This is so because at a symmetric equilibrium a group captures only $(1 / n)$-th of the returns of its investment. This way the net return of investment and the incentive to invest vanishes with increasing fractionalization. Stagnation becomes more likely in fractionalized societies.

\section{Economic Stagnation and Social Conflict}

If productivity is sufficiently low or fractionalization is sufficiently high, the economy stagnates. Stagnation, however, is not sufficient for conflict. This will be shown next together with determinants of the intensity conflict if it arises. The symmetric Nash equilibrium of stagnation is particularly easy to analyze. Because nobody invests, groups solve a static problem of consumption maximization. Consumption is obtained from (1) and (2) by setting $e_{i}=0$.

$$
c_{i}=\left(1-\tau_{i}\right) \frac{\alpha+\tau_{i}}{n \alpha+\sum_{j=i}^{n} \tau_{j}} A k n .
$$

The first order condition w.r.t. $\tau_{i}$ requires

$$
\left[\left(1-\tau_{i}\right)-\left(\alpha+\tau_{i}\right)\right]\left(n \alpha+\sum_{j=i}^{n} \tau_{j}\right)-\left(1-\tau_{i}\right)\left(\alpha+\tau_{i}\right)=0
$$

Applying symmetry we get equilibrium fighting effort $\tau^{*}$.

$$
\tau_{i}=\tau^{*} \equiv \max \left\{0, \frac{\phi-\alpha}{\phi+1}\right\}, \quad \phi \equiv \frac{n-1}{n}
$$

for all $i=1, \ldots, n$. Here, $\phi$ is equivalent to the index of social fractionalization. This index provides the probability that two people randomly drawn from the population belong to different social groups, i.e. $\phi=1-\sum_{i=1}^{n}(1 / n)^{2}$. Inspection of (15) proves the following result.

Theorem 4. a) There exists a unique symmetric Nash equilibrium of conflict if $(\phi-\alpha)>0$, i.e. if a society is sufficiently fractionalized and appropriation opportunities are sufficiently large. b) At a conflict equilibrium, fighting intensity increases with increasing social fractionalization and increasing opportunities to appropriate (decreasing $\alpha$ ). 
The result that conflict intensity is higher in largely fractionalized societies is a special application of a general regularity in conflict theory that has been observed among others by Hirshleifer (1995) and Grossman (2001). More groups in symmetric society implies more outgroup members to contest resources with. It thus implies higher returns on fighting for every group and induces higher fighting effort in equilibrium. This can best be seen by obtaining the marginal return on fighting from (1). After applying symmetry the expression becomes $(n-1) /\left[n\left(\alpha+\tau_{i}\right)\right]$ and we can verify immediately that marginal returns are increasing in the degree of social fractionalization.

Given the degree of fractionalization, the model predicts that those societies are particularly prone to conflict whose resources are easily appropriated through fighting. With the expectation that natural resources are comparatively easy to appropriate, the result is supported by the empirical literature on the determinants of civil war, see Fearon and Laitin (2003) and Collier and Hoeffler (2004). If we imagine the equilibrium outcome for the mode of appropriation (violent or peaceful) as social norm or "institution" the result is also loosely connected to Isham et al.'s (2005) finding that the ease of resource appropriation matters for economic performance through its impact on institutions and violence.

While confirming the special role of natural resources, Alexander and Harding (2005) have also identified ethnic composition of society as significant determinant of civil war. Their inference, however, that this result questions the "greed rather than grievance" conclusion derived from the (seeming) insignificance of ethnicity variables in the earlier literature is not valid. Here, we have seen that whether peace or conflict prevails depends crucially on social composition but not directly on income. At the same time conflict is completely driven by economic opportunities, i.e. by "greed" according to the terminology of the referred literature.

The result that not only the occurrence but also the intensity of conflict depends on social diversity is supported by Easterly (2001b) who found an association between the number of civil war casualties and ethnic fractionalization. Generally the empirical literature focusses on civil wars, i.e. conflicts that involve a sufficiently large number of deaths, so that other "milder" forms of social conflict that would still be consistent with our contest success function cannot be confronted with empirical facts.

Interestingly, Nash equilibria of conflict and growth may exist simultaneously. If this is the case, it becomes possible to end up in the dominated conflict equilibrium "by mistake". Consider, for example, a socio-economy where productivity $A$ is high enough so that positive growth according to (12) exists. Assume that the "good" equilibrium of growth and mutual peace is 
indeed attained initially. Now, one group $j$ trembles and sets by mistake $\tau_{j}>0$. If groups, $i=1, \ldots, n$ react according to their best response (14) the system ends up in equilibrium (15). Maybe resources are hard to appropriate and $\tau^{*}$ turns out to be zero. Yet, if resources are easily appropriated so that $\tau^{*}>0$, the socio-economy becomes trapped in stagnation and conflict.

How likely is it that equilibria of growth and conflict exist simultaneously? Intuitively, we expect from the fact that returns of investment are decreasing in $n$ and returns on fighting are increasing in $n$ that both equilibria exist for an intermediate value of $n$. The number of groups has to be sufficiently small for investment to pay off in an equilibrium of peace and yet sufficiently large for fighting to be worthwhile if the economy stagnates. Inspection of (12) and (15) shows that model parameters must be such that $1 /(1-\alpha)<n<A / \rho$, i.e. the model economy must be characterized by easily appropriable resources, high general productivity, and an intermediate degree of social fractionalization.

Finally, note that it is much harder to return from conflict to peace "by mistake". This would require that all groups tremble and set $\tau=0$ simultaneously. Alternatively, we need a mutual assurance to behave peacefully. Thus, while conflict can arise spontaneously, pacification may need peace building institutions.

\section{Asymmetric Groups}

From now on we abandon the symmetry assumption and investigate behavior of groups of asymmetric size. To keep the analysis tractable we have to restrict it to two groups, i.e. a society consisting of a majority and a minority. The most obvious association with the two-group scenario is that of conflict between a group represented by the government and a group of rebels, i.e. civil war. Two other violent varieties, however, are found with almost equal frequency in real life. The newly established Uppsala Conflict Data Program (Eck, 2003) identifies 37 percent of the recorded cases of intra-state violence as state-based (government against rebels), 33 percent as non- state (warring rebel groups) and 30 percent as one-sided (the violent actor is either the government or a rebel organization). ${ }^{7}$

Below it will be shown that without symmetry assumption it nevertheless continues to be individually rational not to fight and invest simultaneously. Yet, the macro implication that growth happens only to peaceful societies is no longer valid because one group can turn out to be aggressive while the other one behaves peacefully and invests. Asymmetric behavior

${ }^{7}$ Figures for the year 2003. Similar figures are found for the year 2002. The database - although more detailed than others - collects only cases with more than 25 battle-related killings so that only the most violent interpretation of the model's appropriation contest can be confronted with the data. The database does also not contain information about other more secretive forms of organized violence. 
renders the model less easily refuted by reality where growth and conflict are sometimes observed simultaneously. These cases are typically not characterized by a whole nation at war but by a fighting minority and a peaceful majority. Before we investigate one-sided conflict and statebased conflict in Section 6 and 7 in more detail we now set up the asymmetric model and discuss equilibria of mutual peace and violence.

Consider a society of two groups of size $s$ and $(1-s), s \in(0,1)$. When $s$ is close to one or close to zero a small minority faces a large majority. For $s=1 / 2$ the society consists of two groups of equal size and is equivalent to the symmetric case discussed above (with $n=2$ ). The index of social fractionalization, i.e. the probability to draw randomly two members of different groups, is calculated as $1-s^{2}-(1-s)^{2}=2(1-s) s$. It is first increasing in $s$, then decreasing, and assumes maximum for $s=1 / 2$, i.e. the polarized society consisting of two large groups of equal size. To further facilitate analysis we focus on logarithmic utility, $U\left(c_{i}\right)=\log \left(c_{i}\right)$. The contest success functions are

$$
k_{1}=\frac{s\left(\alpha+\tau_{1}\right)}{\alpha+s \tau_{1}+(1-s) \tau_{2}} k, \quad k_{2}=\frac{(1-s)\left(\alpha+\tau_{2}\right)}{\alpha+s \tau_{1}+(1-s) \tau_{2}} k
$$

They imply that in times of society-wide peaceful behavior $\left(\tau_{1}=\tau_{2}=0\right)$, group 1 gets the share $s$ of resources and group 2 the share $(1-s)$ implying that every person is identically equipped irrespective of its social provenience.

Groups maximize intertemporal utility from consumption of their representative member given the production function (2), the state equation (3) and the contest success function (16). Group 1 maximizes

$$
\begin{aligned}
L_{1} & =\log \left(c_{1}\right) \\
& +\lambda_{1}\left\{\left(1-\tau_{1}\right) \frac{s\left(\alpha+\tau_{1}\right)}{\alpha+s \tau_{1}+(1-s) \tau_{2}} A k+\left(1-\tau_{2}\right) \frac{(1-s)\left(\alpha+\tau_{2}\right)}{\alpha+s \tau_{1}+(1-s) \tau_{2}} A k-s c_{1}-(1-s) c_{2}\right\} \\
& +\mu_{1}\left[\left(1-\tau_{1}\right) \frac{s\left(\alpha+\tau_{1}\right)}{\alpha+s \tau_{1}+(1-s) \tau_{2}} A k-s c_{1}\right],
\end{aligned}
$$

and group 2 maximizes a similar Hamiltonian $L_{2}$. Note that $c_{1}$ and $c_{2}$ denote per capita consumption so that group 1 (consisting of $s$ members) consumes $s c_{1}$ and group 2 consumes $(1-s) c_{2}$.

We begin by showing how Theorem 1 has to be modified for an asymmetric society.

Theorem 5. In an economy with unenforceable property rights populated by two groups of unequal size no group is simultaneously investing $\left(e_{i}>0\right)$ and fighting $\left(\tau_{i}>0\right)$. This implies that society-wide conflict $\left(\tau_{i}>0\right.$ for all $\left.i\right)$ and growth cannot be observed simultaneously. 
Proof. The first order conditions for fighting are $\left(\partial L_{i} / \partial \tau_{i}\right) \tau_{i}=0, \partial L_{i} / \partial \tau_{i}<0, i=1,2$, with

$$
\begin{aligned}
& \frac{\partial L_{1}}{\partial \tau_{i}}=\frac{A k}{\left(\alpha+s \tau_{1}+(1-s) \tau_{2}\right)^{2}}\left\{\lambda_{1}\left[\left(1-\tau_{1}\right) s-s\left(\alpha+\tau_{1}\right)\right]\left(\alpha+s \tau_{1}+(1-s) \tau_{2}\right)\right. \\
& -\lambda_{1}\left(1-\tau_{1}\right) s^{2}\left(\alpha+\tau_{1}\right)-\lambda_{1}\left(1-\tau_{2}\right) s(1-s)\left(\alpha+\tau_{2}\right)+\mu_{1}\left[\left(1-\tau_{1}\right) s-s\left(\alpha+\tau_{1}\right)\right] \\
& \left.\times\left(\alpha+s \tau_{1}+(1-s) \tau_{2}\right)-\lambda_{1}\left(1-\tau_{1}\right) s^{2}\left(\alpha+\tau_{1}\right)\right\} \\
& \frac{\partial L_{2}}{\partial \tau_{2}}=\frac{A k}{\left(\alpha+s \tau_{1}+(1-s) \tau_{2}\right)^{2}}\left\{\lambda_{2}\left[\left(1-\tau_{2}\right)(1-s)-(1-s)\left(\alpha+\tau_{2}\right)\right]\left(\alpha+s \tau_{1}+(1-s) \tau_{2}\right)\right. \\
& -\lambda_{2}\left(1-\tau_{2}\right)(1-s)^{2}\left(\alpha+\tau_{2}\right)-\lambda_{2}\left(1-\tau_{1}\right) s(1-s)\left(\alpha+\tau_{1}\right)+\mu_{2}\left[\left(1-\tau_{2}\right)(1-s)-(1-s)\left(\alpha+\tau_{2}\right)\right] \\
& \left.\times\left(\alpha+s \tau_{1}+(1-s) \tau_{2}\right)-\lambda_{2}\left(1-\tau_{2}\right)(1-s)^{2}\left(\alpha+\tau_{2}\right)\right\}
\end{aligned}
$$

First suppose that both groups invest and fight so that $\tau_{i}, e_{i}>0$ and $\mu_{i}=\partial L_{i} / \partial \tau_{i}=0$ for both groups. The only solution of (17) is $\tau_{1}=\tau_{2}=-a$, contradicting the initial supposition of positive fighting activity. Now, suppose qualitatively distinct behavior. Without loss of generality let group 1 be peaceful $\left(\tau_{1}=0\right)$. Suppose that group 2 is simultaneously investing and fighting $\left(\tau_{2}>0\right)$. Setting $\partial L_{2} / \partial \tau_{2}=\mu_{2}=\tau_{1}=0$ in $(17 \mathrm{~b})$ provides $\tau_{2}=-a /(1+\sqrt{s})$ and $\tau_{2}=-a /(1-\sqrt{s})$. Because $0<s<1$, the solution candidates violate the initial supposition that fighting is positive. Thus investors never fight so that society-wide conflict and growth cannot happen simultaneously.

The qualified no-peace-no growth theorem refers to mutual peace and allows for an important special case of asymmetric behavior according to which a peaceful group invests and generates growth although another non-investing group appropriates resources non-peacefully. These equilibria will be investigated in the next section. Here, we continue by considering qualitatively similar behavior of both groups. We begin by investigating conditions for society-wide investment. $^{8}$

Theorem 6. If in the society of two groups both groups decide to invest, then irrespective of social affiliation everyone's consumption grows at rate $g_{c}=A-2 \rho$. Members of the majority, however, invest more than members of the minority.

Proof. Without fighting, the equation of motion for economy-wide capital resulting from (1) and (2) is

$$
\dot{k}=A k-s c_{1}-(1-s) c_{2}
$$

Positive investment implies $\mu_{i}=0$ for $i=1,2$. The first order condition for consumption of

\footnotetext{
${ }^{8}$ We focus on Nash equilibria. Note, however, that the Markovian Stackelberg solution coincides with the Markovian Nash solution because the strategy of a group depends on strategies of other groups only through the state of the system.
} 
group 1 is $1 / c_{1}-s \lambda_{1}=0$ and its costate equation (given that groups follow time-consistent Markovian consumption strategies) is $\lambda_{1}\left[A-(1-s) c_{2}^{\prime}(k)\right]=\lambda_{1} \rho-\dot{\lambda}_{1}$. Differentiating the first order condition with respect to time, using the results to eliminate $\lambda_{1}$ and $\dot{\lambda}_{1}$ in the costate equation, using the fact that $c_{i}^{\prime}(k)=\dot{c}_{i} / \dot{k}$, and inserting the equation of motion for capital we obtain

$$
c_{1}^{\prime}(k)=\frac{\left[A-\rho-(1-s) c_{2}^{\prime}(k)\right] c_{1}(k)}{A k-s c_{1}(k)-(1-s) c_{2}(k)} .
$$

Analogously, we obtain for group 2

$$
c_{2}^{\prime}(k)=\frac{\left[A-\rho-s c_{1}^{\prime}(k)\right] c_{2}(k)}{A k-s c_{1}(k)-(1-s) c_{2}(k)} .
$$

The solution for equilibrium consumption strategies is

$$
s c_{1}=(1-s) c_{2}=\rho k
$$

Both groups consume the same quantity, which is shared by $s$ and $(1-s)$ members, respectively. This implies that members of the larger group consume less and invest more at any given level of $k$. Resubstituting $c_{i}$ and $c_{i}^{\prime}$ into the costate equation provides the growth rate $g_{c}$.

The minority invest comparatively little because it knows that the returns of its investment will be mainly appropriated by members of the large other group. Likewise the majority knows that the returns of its investment are mainly appropriated by group affiliates with whom they co-operate and thus invests more.

If neither minority nor majority invests, the economy stagnates and groups solve a static problem of consumption maximization. The first order conditions for optimal fighting read

$$
\begin{aligned}
& 0=\left(1-\tau_{1}\right)\left[1-\frac{s\left(\alpha+\tau_{1}\right)}{\alpha+s \tau_{1}+(1-s) \tau_{2}}\right]-\left(\alpha+\tau_{1}\right)=F\left(\tau_{1}, \tau_{2}, \alpha, s\right) \\
& 0=\left(1-\tau_{2}\right)\left[1-\frac{(1-s)\left(\alpha+\tau_{2}\right)}{\alpha+s \tau_{1}+(1-s) \tau_{2}}\right]-\left(\alpha+\tau_{2}\right)=G\left(\tau_{1}, \tau_{2}, \alpha, s\right)
\end{aligned}
$$

We know already from symmetric equilibrium that stagnation does not necessarily imply conflict i.e. an interior solution for (21). Delegating the case of unilateral conflict to the next section we now focus on group aggressiveness in an equilibrium of mutual conflict.

Theorem 7. At an equilibrium of mutual conflict the intensity of fighting decreases with group size. The minority fights harder.

This result - proven in the Appendix - is known from the conflict literature as the "Paradox of Power" (Hirshleifer, 1991). The intuition is similar to the symmetric case. Members of a 
small group have relatively little group affiliates to share resources cooperatively with and more out-group members to appropriate from. Consequently marginal returns on fighting are higher for small groups inducing them to fight harder.

\section{Predatory Minorities and the Matthew Effect}

From Theorem 7 we may already infer who will be investor and who will be appropriator if qualitatively distinct social behavior occurs. Indeed, the question has a clear-cut answer (proven in the Appendix).

Theorem 8. If the economy is populated by a group of peaceful investors and a group of violent appropriators, then the aggressive group is a social minority.

With one-sided aggressive behavior we are changing the focus of analysis from an all-out appropriation contest to low-intensity conflict. A large peaceful majority is challenged by a small aggressive minority. The low-intensity assessment does not imply that a single member of the minority spends only little time on conflict. Quite the opposite is true as will be shown below. Minority members are devoting large parts of their time endowment on aggressive appropriation. The low intensity of conflict results from the fact that only a small fraction of society belongs to the aggressive minority such that the appropriated share remains small from a macro perspective. Facing only a relatively small loss through appropriation the majority behaves peacefully, devotes all time to production, and perhaps even invests.

The focus on low-intensity, one-sided conflict makes it harder to interpret the non-cooperative groups as ethnicities and blurs further the anyway fuzzy border between paramilitary activities, guerilla warfare, and organized crime. Sometimes the name of the violent group suggests a formation along political ideas (for example the FARC in Columbia, the LRA in Uganda, or the RUF in Sierra Leone) and sometimes not (the Yakuza, the Triads, the Mafia). In any case appropriation is the purpose of the groups violent activity. Interestingly, also organized crime frequently forms up along ethnic lineages and associations between specific families (for Africa see UN, 2005). In many African conflicts the appropriation motive behind the political veil is particularly evident because "there is no landlord from whom to free the masses" (Mkandawire, 2002) and violence is directed against the peaceful rural population.

Turning towards the model, assume without loss of generality that group 2 is the larger one and parameters are such that it behaves peaceful. If it invests, we obtain (19b) from the first order condition for consumption, state equation, and costate equation. The interior solution (20) implies that group 2 consumes the same as it would in mutual peace. However, it gets 
a lower share of resources when group 1 is fighting. Taken together group 2's investment rate is lower when group 1 is fighting. Because group 1 is not investing, economic growth is solely determined by investment of group 2 and obtained as

$$
g_{c}=\max \left\{0, \frac{\alpha(1-s) A}{\alpha+s \tau_{1}}-\rho\right\}
$$

Economic growth is decreasing in the size of the minority $(s)$ and its fighting intensity $\left(\tau_{1}>0\right)$. Existence of a fighting minority further reduces capital productivity (which would be $(1-s) A$ in a peaceful society and $A$ if, additionally, property rights were secure). If the fighting group is sufficiently large or its fighting sufficiently intense, the majority does not invest even though productivity would be high enough to guarantee investment if property rights were secure (i.e. $A>\rho$ but $\left.\alpha(1-s) A /\left(a+s \tau_{1}\right)<\rho\right)$. If the majority does not invest, appropriation opportunities determine whether it also engages in conflict or whether unilateral conflict prevails.

Determining the equilibrium intensity of unilateral fighting is a little more complicated since the fighting group has to take into account the indirect effect of its aggressive behavior on the state equation i.e. its future appropriation opportunities. The following is proven in the Appendix.

Theorem 9. If unilateral conflict exists, then fighting effort is decreasing in productivity $(A)$ and increasing in impatience $(\rho)$.

Productivity has now an impact on conflict intensity because it affects investors and appropriators differently. Conflict is especially intense in societies that populate an economy with low productivity. Intuitively, the result is explained as follows. The appropriating minority takes into account the negative feedback effect that its behavior has on investment of the peaceful group and therewith on their own future consumption. A fall of productivity lowers growth and future appropriation possibilities and increases the incentive to appropriate now. With this intuition in mind it is also obvious why a more impatient group fights harder: the instantaneous appropriation gain receives a large weight in utility compared to the induced future losses.

In sociology it is sometimes referred to a situation in which benefits and harms accrue disproportionally to rich and poor as a Matthew effect in an allusion to a verse in the gospel: "For whoever has, to him shall be given and he shall have more abundance; but whoever has not, from him shall be taken away even that which he has."(Bible, Matthew 13:12). Theorem 9 rationalizes a literally-taken Matthew effect.

The result that in particular low productivity countries are afflicted by conflict provides a theoretical foundation for Rodrik's (1999) hypothesis that the poor growth performance of many less developed countries in the 1970s is not sufficiently explained by the negative productivity 
(terms of trade) shocks received but by social conflict that these shocks induced. Rodrik finds empirical support for this hypothesis in a cross-country study using an interaction term of macro shocks, institutional quality, and ethnic diversity.

When the size of a minority decreases its members fight harder but also a smaller fraction of society belongs to the aggressive group so that it is not a priori clear how social fractionalization affects aggregate conflict. The consequences of groups size on society-wide conflict and macrobehavior are now illustrated with some numerical solutions of the model. Table 1 shows three different economies and four different societies. We consider a very small minority $(s=0.01)$, a ten percent minority $(s=0.1)$, a large minority $(s=1 / 3)$, and two groups of equal size $(s=1 / 2)$. The time preference rate is set to 0.02 in all examples.

The economy on the left faces a value of general productivity of 0.035 implying that it would grow at a rate of 1.5 percent if property rights were secure. Appropriation opportunities are relatively large indicated by a low value of $\alpha$ of 0.05 . Under these circumstances a very small social minority (the rebels) spends 41 percent of their time appropriating wealth. Although the minority is very aggressive it has only little effect on behavior of the other group and on macro performance because it is so small. From society-perspective "only" 0.4 percent of total time are spent on fighting. The majority behaves peacefully and invests. The economy grows at a rate of 1.2 percent, i.e. 0.3 percentage points lower than it could under secure property rights.

TABle 1: Productivity, Appropriation Opportunity, and Conflict Intensity

\begin{tabular}{cccccccccccccc}
\hline \hline & \multicolumn{4}{c}{$A=0.035, \alpha=0.05$} & \multicolumn{4}{c}{$A=0.045, \alpha=0.05$} & \multicolumn{3}{c}{$A=0.035, \alpha=0.5$} \\
$s$ & 0.01 & 0.1 & $1 / 3$ & $1 / 2$ & 0.01 & 0.1 & $1 / 3$ & $1 / 2$ & 0.01 & 0.1 & $1 / 3$ & $1 / 2$ \\
\hline$\tau_{1}$ & 0.41 & 0.18 & 0.32 & 0.30 & 0.40 & 0.14 & 0.02 & 0 & 0.20 & 0.11 & 0 & 0 \\
$\tau_{2}$ & 0 & 0 & 0.18 & 0.30 & 0 & 0 & 0 & 0 & 0 & 0 & 0 & 0 \\
$e_{1} / k$ & 0 & 0 & 0 & 0 & 0 & 0 & 0 & 0.25 & 0 & 0 & 0 & 0 \\
$e_{2} / k$ & 1.20 & 0.33 & 0 & 0 & 2.13 & 1.14 & 0.72 & 0.25 & 1.50 & 1.08 & 0.33 & 0 \\
$\Delta g_{c}$ & 0.30 & 1.17 & 1.50 & 1.50 & 0.38 & 1.35 & 1.78 & 2.00 & 0.05 & 0.42 & 1.17 & 1.50 \\
\hline \hline
\end{tabular}

$\rho=0.02$. The last row, $\Delta g_{c}$, shows the loss of growth against an identical economy with secure property rights. Investment rates and loss of growth are displayed in percentage points.

Qualitatively the picture does not change when 10 percent of the population $(s=0.1)$ belong to the minority. The majority still behaves peaceful and invests. While individual aggressive behavior decreases, conflict becomes more intense from the macro perspective. The society spends now 1.8 percent of total time on fighting. The resulting loss through violent appropriation is substantially higher and low investment supports only a meagre growth of rate of 0.33 percent. 
1.17 percentage points of growth are lost through conflict and unenforceable property rights.

When $1 / 3$ of society belongs to the minority the behavior of the majority changes qualitatively. In this case its loss through appropriation by the other group is so high that it gives up investment and engages also in contest. The Paradox of Power operates and the minority fights harder. Overall, the society spends 23 percent of its time on fighting. The economy stagnates. The last row of the left panel illustrates that conflict intensity is highest when the country is populated by a highly polarized society of two equally sized groups. In that case 30 percent of total time are spent on appropriation contest. Because the index of fractionalization rises with $s$ (and assumes a maximum at $s=1 / 2$ ), the results confirm our previous findings for symmetric societies. Growth decreases and conflict intensity increases with increasing fractionalization.

The middle panel in Table 1 considers the same four societies populating an economy of higher overall productivity. A equals 0.045 and under secure property rights the economy could grow at a rate of 2.5 percent. If both groups are of significant size, the cost of lost production and foregone growth opportunities through conflict is sufficiently high so that society-wide peace prevails. Nevertheless the society suffers from unenforceable property rights and both groups invest relatively little. The economy grows at a rate of 0.5 percent, two percentage points less than it could grow with secure property rights. For the case of a minority of intermediate size $(s=0.1)$ we observe the Matthew effect. A fall in productivity (reading the table from the middle to the left) provokes more conflict through a more aggressive minority, which further lowers investment of the majority and thus growth.

The right panel shows results when the resource is harder to appropriate $(\alpha=0.5)$ reflecting, for example, a capital stock that consists to a lesser extent of natural resources. As for the case of higher productivity, an engagement in conflict is not worthwhile when both groups are of significant size. Investment, however, remains low or absent.

\section{Non-Benevolent Social Elites and Mass Resistance}

So far we have assumed that groups are identical in their inherent appropriative power. Any asymmetry resulted from different group size only. While this assumption is useful to isolate the impact of social composition on group behavior and economic performance, it abstracts from the fact that frequently one group enjoys more social power. We can think of a state representing the interests of this group's members. Of course, such a state is not a benevolent one. It is an appropriative, non-benevolent, and possibly violent state. At the extreme the state is a monopoly of violence used to appropriate wealth of its citizens, the other, powerless group 
of society. ${ }^{9}$

Let $s<1 / 2$, and let the smaller group be equipped with larger inherent power reflected by the following contest success functions.

$$
\frac{k_{1}}{k}=\left(1-\tau_{1}\right) \frac{s\left(\alpha+\tau_{1}\right)}{\alpha+s \tau_{1}+(1-s) \lambda \tau_{2}}, \quad \frac{k_{2}}{k}=\left(1-\tau_{2}\right) \frac{(1-s)\left(\alpha+\lambda \tau_{2}\right)}{\alpha+s \tau_{1}+(1-s) \lambda \tau_{2}}, \quad \lambda \in[0,1] .
$$

The new parameter $\lambda$ measures relative appropriative success of group 2, the society's majority. For $\lambda=1$, the model reduces to the one of the previous sections where groups possess identical inherent power. With decreasing $\lambda$ the majority loses power. A given effort in the appropriative activity yields less appropriative returns. At $\lambda=0$, the majority is powerless in the sense that the time spent on fighting is ineffective. The first group has monopoly power of violence. For small $s$, we can think of group 1 as an aristocracy, oligarchy, or ruling elite.

Inspect (23) to verify that the model collapses to the one already discussed in case of mutual peace or peaceful behavior of the majority. The interesting equilibrium is the one of mutual conflict. It could be characterized as mass resistance against a predatory state. Setting $e_{i}=0$ (because mutual conflict precludes investment), inserting (23) in (2) and maximizing consumption provides the first order conditions

$$
\begin{aligned}
& 0=\left(1-\tau_{1}\right)\left[1-\frac{s\left(\alpha+\tau_{1}\right)}{\alpha+s \tau_{1}+(1-s) \lambda \tau_{2}}\right]-\left(\alpha+\tau_{1}\right)=F\left(\tau_{1}, \tau_{2}, \alpha, s, \lambda\right) \\
& 0=\left(1-\tau_{2}\right)\left[1-\frac{(1-s)\left(\alpha+\lambda \tau_{2}\right)}{\alpha+s \tau_{1}+(1-s) \lambda \tau_{2}}\right]-\left\{\frac{\alpha+\tau_{2}}{\lambda}\right\}=G\left(\tau_{1}, \tau_{2}, \alpha, s, \lambda\right)
\end{aligned}
$$

Because the model has not changed in structure with respect to $s$, Theorem 7 on group size and fighting intensity continues to hold. Additionally, an interesting result with respect to the power of the masses can be derived (proven in the Appendix).

Theorem 10. Consider a society of an inherently strong minority and a weak majority. If an equilibrium of mutual conflict exists, then increasing power of the majority a) leads unambiguously to increasing violence of the minority, and b) leads to increasing violence of the majority given that it is initially sufficiently weak ( $\lambda$ sufficiently small).

If the social majority is initially sufficiently weak, a power extension leads to higher absolute returns in contest, implying more defensive success against the appropriative group. Consequently, the majority defends more, and the predatory minority increases appropriation efforts

\footnotetext{
${ }^{9}$ Two particularly impressive examples for a states under control of violent appropriators are Liberia under the presidency of Charles Taylor (1997-2003) and Sierra Leone when the RUF's leader Foday Sankoh got control over the precious mineral department of the government. More subtle methods used by malevolent dictators to appropriate from the masses are discussed in Acemoglu et al. (2004) in their introduction to a model that explains the extraordinary longevity of some kleptocrats.
} 
in order to maintain a certain level of consumption. Because both social groups raise their fighting intensities, a corollary of the theorem follows immediately.

Corollary 1. Increasing power of a social majority increases the intensity of society-wide conflict given that the majority is initially sufficiently weak.

Yet, we cannot rule out analytically that just the opposite may happen. The opposite case requires that a majority is sufficiently strong albeit weaker than the minority. It may then react to increasing power with decreasing conflict. For an intuitive explanation reconsider equation (24b), which measures the net marginal return on fighting for group 2. The first term in (24b) reflects the gross marginal return on appropriation. The second term in braces describes the marginal loss in production induced by an additional unit of time devoted to conflict. The derivative w.r.t. $\lambda$ of the whole expression is

$$
\frac{\partial G}{\partial \lambda}=-\frac{(1-s) s\left(1-\tau_{2}\right)\left(\alpha+\tau_{1}\right) \tau_{2}}{\left[\alpha+s \tau_{1}+(1-s) \lambda \tau_{2}\right]^{2}}+\frac{\alpha}{\lambda^{2}}
$$

Increasing power of the masses lowers the time-loss in production because the same amount of resources can be appropriated (or defended against appropriation) with less fighting effort. This effect is captured by the last term in (25). It is the dominating effect if the majority is sufficiently weak (let $\lambda$ approach zero to see this). For a sufficiently strong majority, however, it cannot be ruled out that the first term overcompensates the second term. The negative first term is another example for the Paradox of Power. Increasing inherent group power reduces marginal returns in contest. Consequently the group shifts some time from fighting to production. Considering decreasing $\lambda$ the result can be put differently: deprivation of a sufficiently strong majority increases fighting effort i.e. it leads to mass rebellion.

TABLE 2: Social Power AND CONFLict

\begin{tabular}{|c|c|c|c|c|c|c|c|c|c|}
\hline \multirow[b]{2}{*}{$s$} & \multicolumn{3}{|c|}{$\lambda=1$} & \multicolumn{3}{|c|}{$\lambda=1 / 3$} & \multicolumn{3}{|c|}{$\lambda=1 / 5$} \\
\hline & 0.01 & $1 / 3$ & $1 / 2$ & 0.01 & $1 / 3$ & $1 / 2$ & 0.01 & $1 / 3$ & $1 / 2$ \\
\hline$\tau_{1}$ & 0.41 & 0.32 & 0.30 & 0.41 & 0.27 & 0.24 & 0.41 & 0.24 & 0.21 \\
\hline$\tau_{2}$ & 0 & 0.18 & 0.30 & 0 & 0.24 & 0.38 & 0 & 0.20 & 0.37 \\
\hline
\end{tabular}

Table 2 illustrates the results numerically. It considers three possible social divisions with alternative power of the second group. The left panel repeats the left panel from Table 1, i.e. $A=0.035, \rho=0.02$, and $\alpha=0.05$ and equally strong social groups. In the middle and right panel the second group is weaker. Results remain unchanged in case of $s=0.01$, i.e. when a 
small rebel group (or a non-benevolent dictator) receives a further power increase. Given that both groups are of significant size $(s=1 / 3, s=1 / 2)$, however, we observe the above explained non-linear response to a fall of social power. A partial deprivation of an inherently strong group (a fall from $\lambda=1$ to $\lambda=1 / 3$ ) increases its fighting efforts. Following a further deprivation (from $\lambda=1 / 3$ to $\lambda=1 / 5)$, however, the weak group reduces resistance against appropriation. In other words (reading the table from right to left), a partial empowerment of an initially weak group increases social conflict. Further empowerment of an already sufficiently strong group lowers society-wide conflict. The mechanism rationalizes the historical observation of drastic power concessions (see e.g. South Africa). Once an initially powerless majority gains "somehow" some power it can be in the elite's interest to make further power concessions because this reduces aggressiveness of the majority, improves economic performance, and yields higher consumption for everybody in society including the member of the minority.

Finally, we extract a general frontier that separates the three regimes of peace, unilateral-, and society-wide conflict. For that purpose we solve system (24) for the case when the condition $\tau_{2} \geq 0$ is just binding. This renders a solution for $\tau_{1}$ and a conflict frontier which is most conveniently represented in the $(s, \lambda)$ space. Of course, the solution applies only for $s \leq 1 / 2$, i.e. as long as the powerful elite is not the majority of society. Taken together we have

$$
s=\min (s(\lambda), 1 / 2), \quad s(\lambda)=\frac{\alpha^{2}(2 \lambda-\alpha)}{(\lambda-\alpha)^{2}+\alpha \lambda^{2}} .
$$

The conflict frontier is shown in Figure 1. The $s(\lambda)$ curve intersects the $\lambda$-axis at $\alpha / 2$ and reaches a maximum where $\lambda=\alpha$ (and $s(\lambda)=1$ ). It is then monotonously falling but not leaving the positive quadrant. Inside the frontier we observe society-wide conflict $\left(\tau_{2}>0\right)$. Outside the majority behaves peacefully $\left(\tau_{2}=0\right)$. We observe unilateral aggression of the powerful group $\left(\tau_{1}>0\right)$ if the majority is very weak and the minority is strong but small (oligarchy) or societywide peace $\left(\tau_{1}=0\right)$ if the minority not too small and the majority is relatively powerful.

The figure confirms the intuition already developed. The possibility of mutual conflict is largest when the majority is of intermediate power. If $\lambda<\alpha / 2$, mutual conflict disappears irrespective of group size because the majority is simply to weak to resist. Implicitly, we can also infer from the Figure that society-wide conflict ceases to exist irrespective of the majority's power when resources are sufficiently hard to appropriate. An increase in $\alpha$ shifts the frontier to the right. For $\alpha=2$ the intersection with the $\lambda$-axis is at $\lambda=1$ implying that mutual conflict disappears entirely. On the other hand, we see that there is always conflict for sufficiently small s. In other words, conflict is more likely when the powerful group is small. 
Figure 1: The Conflict Frontier ( $\lambda$ inherent power of majority, $s$ size of minority)

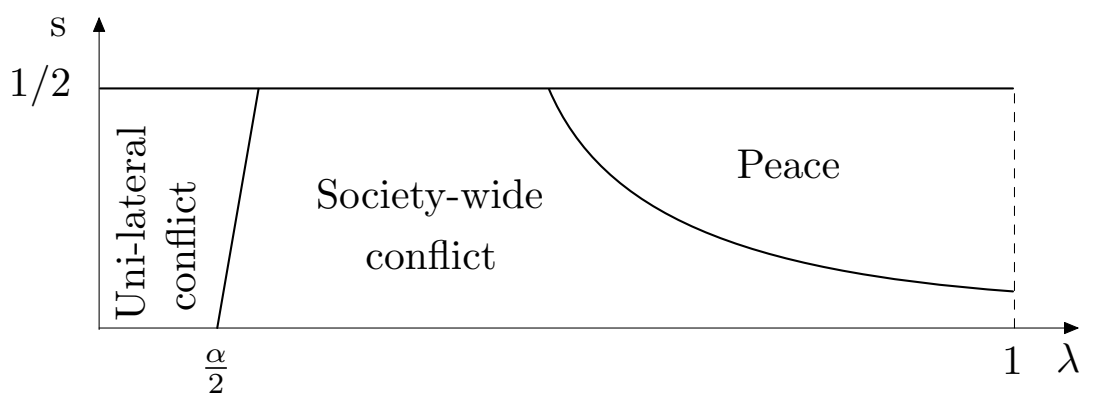

\section{Final Remarks}

This article has shown how social diversity affects the way resources are appropriated when property rights cannot be enforced and how appropriation behavior feeds back through an investment- and conflict channel to long-run economic development. For a society of symmetric groups it has been shown that positive economic development requires a peaceful society. The result is grounded in the individual rationale of not being simultaneously investor in and appropriator of the same resource. An asymmetric society, however, can consist of a group of investors and another group of appropriators. In that case, it has been explained why the social minority turns out to be the aggressive appropriator and the majority behaves peacefully. The majority may even invest (albeit at a low rate). In any case, civil conflict, i.e. violent appropriation behavior of all social groups, prevents economic growth.

If economic growth occurs, it has been explained why it is decreasing in social fractionalization and why countries endowed with easily appropriable natural resources are especially prone to conflict. A Matthew effect has been found according to which a negative productivity shock triggers increasing appropriative conflict which in turn further deteriorates economic performance. With these results the article offers a theory that can explain some empirical regularities found in recent research about Africa's poor economic and social performance (see, for example, Collier and Gunning, 1999, and the literature listed in the Introduction).

Most of the time the investigated society consisted either of a variable number of groups of equal size or of two groups of variable size. Only the last part has tried to extended the analysis towards the behavior of inherently powerful social elites and mass resistance. Recognizing these constraints on social diversity the article has deliberately avoided to use the more ambitious term social structure, leaving it for future analyses that manage to introduce more sophisticated divisions of society into the theory of macroeconomic growth. Here, we can only mention some 
conceivable and desirable directions for future extensions thereby also noting the limitations of the currently available model.

Taking the division of society as given is, of course, a major simplification because we know that groups are in fact socially constructed and vary over time (Anderson, 1983; Barth, 1999). Integrating the process of group formation into a dynamic macroeconomic model would thus constitute a substantial step ahead. Yet, even with the size of groups given an integration of a more advance split-up of society could add great value to the model. For example, only if society consists of three or more groups of unequal size the index of fractionalization differs from the index of polarization (Esteban and Ray, 1994, Montalvo and Reynal-Querol, 2005). In that case the recently published discussion about the effects of polarization versus fractionalization on civil conflict and economic growth (Alesina et al., 2004, Montalvo and Reynal-Querol, 2005) could be confronted with predictions derived from a theoretical model.

It has already been mentioned that the investigated Markov strategies constitute just one (albeit particularly plausible) possibility to investigate social conflict. Trigger strategies, for example, that have been successfully applied to the case of peaceful resource appropriation (Benhabib and Rustichini, 1996, Lindner and Strulik, 2006) could also lead to new and interesting results in the case of appropriation contest. The assumption that there is no conflict within groups is also quite strong. It neglects, for example, agency problems and free-rider behavior, and the general issues of sharing the captured resources within the group and punishing defecting groups members. Of course, an integration of a multi-layered society and networks would make the model more realistic (possibly at the cost of analytical intractability). Finally, it might be worthwhile to note that this has been an economist's article about a topic which is verifiably to a great extent of economic nature, but perhaps not entirely. Economists take preferences as given and search for causes in the constraints. The alternative approach is maybe best summarized by John Lennon's famous words "War is over, if you want it." 


\section{Appendix}

A. General Proof of the no-peace-no-growth result. Let $U$ denote a utility function fulfilling $U^{\prime}>0$ and $U^{\prime \prime}<0$, let $f$ be a production function with $f\left(k_{i}\right)>0$ for $k_{i}>0$ otherwise, and let

$$
\frac{k_{i}}{k}=\frac{g\left(\tau_{i}\right)}{\sum_{j=1}^{n} g\left(\tau_{j}\right)}
$$

be a general form of the contest success function (1) for the representative group $i$. A household's time is normalized to one and is devoted to production and fighting. Hence, a group produces

$$
y_{i}=\left(1-\tau_{i}\right) f\left[\frac{g\left(\tau_{i}\right) k}{\sum_{j=1}^{n} g\left(\tau_{j}\right)}\right] \text {. }
$$

The first order condition for an interior solution of consumption (implying positive investment) is $U^{\prime}\left(c_{i}\right)=$ $\lambda_{i}$ so that $\lambda_{i}>0$. At an interior solution for investment the first order condition for fighting - which cannot be negative - is $\left(\partial L / \partial \tau_{i}\right) \tau_{i}=0$ and $\partial L / \partial \tau_{i} \leq 0$ with

$$
\frac{\partial L_{i}}{\partial \tau_{i}}=\lambda_{i}\left\{\left(1-\tau_{i}\right) \frac{g^{\prime}\left(\tau_{i}\right) f^{\prime}[\cdot] k}{\sum_{j=1}^{n} g\left(\tau_{j}\right)}-f[\cdot]-\sum_{j=1}^{n}\left(1-\tau_{j}\right) \frac{g\left(\tau_{i}\right) g^{\prime}\left(\tau_{j}\right) f^{\prime}[\cdot] k}{\left[\sum_{j=1}^{n} g\left(\tau_{j}\right)\right]^{2}}\right\} .
$$

Applying symmetry the right hand side simplifies to $-\lambda_{i} f[\cdot]$, a negative expression. The Kuhn-Tucker condition requires $\tau_{i}=0$.

B. Proof of of Theorem 7. Partial derivatives of (21) are

$$
\begin{aligned}
& \frac{\partial F}{\partial \tau_{1}}=-\left\{(1-s)\left(\alpha+\tau_{2}\right)\left[\alpha+s+(1-s) \tau_{2}\right]\right\} / N^{2}-1<0 \\
& \frac{\partial F}{\partial \tau_{2}}=\left\{(1-s)\left(\alpha+\tau_{1}\right) s\left(1-\tau_{1}\right)\right\} / N^{2}>0 \\
& \frac{\partial G}{\partial \tau_{1}}=\left\{(1-s)\left(\alpha+\tau_{2}\right) s\left(1-\tau_{2}\right)\right\} / N^{2}>0 \\
& \frac{\partial G}{\partial \tau_{2}}=-\left\{s\left(\alpha+\tau_{1}\right)\left[\alpha+(1-s)+s \tau_{1}\right]\right\} / N^{2}-1<0 \\
& \frac{\partial F}{\partial s}=-\left\{\left(1-\tau_{1}\right)\left(\alpha+\tau_{1}\right)\left(\alpha+\tau_{2}\right)\right\} / N^{2}<0 \\
& \frac{\partial G}{\partial s}=\left\{\left(1-\tau_{2}\right)\left(\alpha+\tau_{1}\right)\left(\alpha+\tau_{2}\right)\right\} / N^{2}>0, \quad \text { where } N \equiv \alpha+s \tau_{1}+(1-s) \tau_{2} .
\end{aligned}
$$

Without loss of generality we consider fighting intensity of group 1. Using the implicit function theorem and Cramer's rule

$$
\frac{\partial \tau_{1}}{\partial s}=\frac{\operatorname{det} J_{1}}{\operatorname{det} J}, \quad \operatorname{det} J=\frac{\partial F}{\partial \tau_{1}} \frac{\partial G}{\partial \tau_{2}}-\frac{\partial F}{\partial \tau_{2}} \frac{\partial G}{\partial \tau_{1}}, \quad \operatorname{det} J_{1}=-\frac{\partial F}{\partial s} \frac{\partial G}{\partial \tau_{2}}+\frac{\partial F}{\partial \tau_{2}} \frac{\partial G}{\partial s} .
$$

Because $\tau_{2} \geq 0, s+(1-s) \tau_{2}>s\left(1-\tau_{2}\right)$, and comparing absolute values, $\left|\partial F / \partial \tau_{1}\right|>\left|\partial G / \partial \tau_{1}\right|$. Similarly, one concludes $\left|\partial G / \partial \tau_{2}\right|>\left|\partial F / \partial \tau_{2}\right|$. Hence, the two negative multipliers of the first term in $\operatorname{det} J$ are larger than the two positive multipliers of the second term. Therewith, $\operatorname{det} J>0$.

$$
\operatorname{det} J_{1}=\frac{\left(\alpha+\tau_{1}\right)\left(\alpha+\tau_{2}\right)}{N^{2}} M_{1}, \quad M_{1} \equiv\left(1-\tau_{1}\right) \frac{\partial G}{\partial \tau_{2}}+\left(1-\tau_{2}\right) \frac{\partial F}{\partial \tau_{2}} .
$$

After some algebra $M_{1}$ simplifies to $M_{1}=-\left(1-\tau_{1}\right)\left(\alpha+\tau_{1}\right) s / N^{3}-\left(1-\tau_{1}\right)<0$, and therewith det $J_{1}<0$ and $\partial \tau_{1} / \partial s<0$.

C. Proof of Theorem 8. Assume without loss of generality that group 1 is fighting and that group 2 is peaceful. Without fighting, group 1 would get the share $s$ of resources, i.e.

$$
\left(1-\tau_{1}\right) \frac{s\left(\alpha+\tau_{1}\right)}{\alpha+s \tau_{1}}>s \quad \Rightarrow \quad\left(1-\tau_{1}\right)\left(\alpha+\tau_{1}\right)>\alpha+s \tau_{1}
$$

for fighting to be worthwhile.

Group 2 produces output

$$
(1-s) \frac{\alpha+\tau_{2}}{\alpha+s \tau_{1}+(1-s) \tau_{2}}\left(1-\tau_{2}\right) A k
$$


The derivative with respect to $\tau_{2}$ taken at $\tau_{2}=0$ has to be negative for that group 2 has no incentive to deviate from peaceful behavior. This requires

$$
(1-\alpha)\left(\alpha+s \tau_{1}\right)-(1-s) \alpha<0 .
$$

Group 1 produces output

$$
s \frac{\alpha+\tau_{1}}{\alpha+s \tau_{1}+(1-s) \tau_{2}}\left(1-\tau_{1}\right) A k .
$$

The derivative with respect to $\tau_{1}$ taken at $\tau_{2}=0$ has to be positive for an incentive for group 1 to fight. This requires

$$
\left(\alpha+s \tau_{1}\right)(1-\alpha)>s\left(\alpha+\tau_{1}\right)\left(1-\tau_{1}\right) .
$$

Now combine (A.2) and (A.3):

$$
s\left(\alpha+\tau_{1}\right)\left(1-\tau_{1}\right)<(1-s) \alpha \quad \Rightarrow \quad\left(1-\tau_{1}\right)\left(\alpha+\tau_{1}\right)<\alpha(1-s) / s .
$$

Use this information in (A.1) to get

$$
\alpha+s \tau_{1}<\alpha(1-s) / s \quad \Rightarrow \quad \alpha<\alpha(1-s) / s \quad \Rightarrow \quad s<1 / 2 .
$$

Group 1 has to be of a size smaller than $1 / 2$, i.e. it has to be a minority.

E. Proof of Theorem 9. Let group 1 be a fighting, non-investing minority. Without investment, $\mu_{1}>0$, and the first order condition for consumption requires

$$
1 / c_{1}=s \lambda_{1}+s \mu_{1}
$$

Taking dynamic interaction through possible investment of the peaceful group into account, the costate equation reads

$$
\lambda_{1}\left\{\left(1-\tau_{1}\right) \frac{s\left(\alpha+\tau_{1}\right)}{\alpha+s \tau_{1}} A+\frac{(1-s) \alpha}{\alpha+s \tau_{1}} A-(1-s) c_{2}^{\prime}(k)\right\}+\mu_{1}\left(1-\tau_{1}\right) \frac{s\left(\alpha+\tau_{1}\right)}{\alpha+s \tau_{1}} A=\lambda_{1} \rho-\dot{\lambda}_{1} .
$$

With positive fighting of group one the first order condition for fighting requires $\partial L_{1} / \partial \tau_{1}=0$. Setting $\tau_{2}=0$ we obtain from eq. (17a)

$$
\frac{\lambda_{1}+\mu_{1}}{\lambda_{1}}\left\{\left[\left(1-\tau_{1}\right)-\left(\alpha+\tau_{1}\right)\right]\left(\alpha+s \tau_{1}\right)-\left(1-\tau_{1}\right) s\left(\alpha+\tau_{1}\right)\right\}=(1-s) \alpha .
$$

Suppose a constant solution $\tau_{1}$ exists. Then, $\left(\lambda_{1}+\mu_{1}\right) / \lambda_{1}$ is constant and (dividing by $\lambda_{1}$ and $\log$ differentiating) we conclude $\dot{c}_{1} / c_{1}=\dot{\lambda}_{1} / \lambda_{1}$ from (A.4). With fighting being constant the appropriated share is constant and consumption grows at equal rates for both groups.

Replacing $\dot{\lambda}_{1} / \lambda_{1}$ with $g_{c}$ from (22) and inserting $(1-s) c_{2}^{\prime}=\rho$ from (20), condition (A.5) becomes

$$
\frac{\lambda_{1}+\mu_{1}}{\lambda_{1}}\left(1-\tau_{1}\right) \frac{s\left(\alpha+\tau_{1}\right)}{\alpha+s \tau_{1}} A=\rho .
$$

Inserting (A.6) in (A.7) provides

$$
\begin{aligned}
& 0=F\left(\tau_{1}, \alpha, A, \rho\right) \equiv \alpha\left(1-\tau_{1}\right)(1-s) s\left(\alpha+\tau_{1}\right)(A / \rho)-\left[\left(1-\tau_{1}\right)-\left(\alpha+\tau_{1}\right)\right]\left(\alpha+s \tau_{1}\right)^{2} \\
& +\left(1-\tau_{1}\right) s\left(\alpha+\tau_{1}\right)\left(\alpha+s \tau_{1}\right) .
\end{aligned}
$$

The derivative w.r.t. $\tau_{1}$ is

$$
\begin{aligned}
& \alpha(1-s) s\left[\left(1-\tau_{1}\right)-\left(\alpha+\tau_{1}\right)\right] A / \rho+B, \quad \text { where } B \equiv 2\left(\alpha+s \tau_{1}\right)^{2}-2 s\left[\left(1-\tau_{1}\right)-\left(\alpha+\tau_{1}\right)\right]\left(\alpha+s \tau_{1}\right) \\
& +s^{2}\left(1-\tau_{1}\right)\left(\alpha+\tau_{1}\right)+s\left(1-\tau_{1}\right)+s\left(1-\tau_{1}\right)\left(\alpha+s\left(\tau_{1}\right)-s^{2}\left(\alpha+\tau_{1}\right)\left(\alpha+s \tau_{1}\right) .\right.
\end{aligned}
$$

Inspection of (A.8) shows that $\left[\left(1-\tau_{1}\right)-\left(\alpha+\tau_{1}\right)\right]>0$ for existence of a positive solution for $\tau_{1}$. Since $A>\rho$ (otherwise the optimization problem has no positive solution when property rights are secure), it is sufficient to show that

$$
\alpha(1-s) s\left[\left(1-\tau_{1}\right)-\left(\alpha+\tau_{1}\right)\right]+B
$$


is positive for $\partial F / \partial \tau_{1}>0$. This expression simplifies to

$$
\alpha^{2}\left(2+s^{2}\right)+s \tau_{1}\left(4 \alpha+2 \alpha s+3 s \tau_{1}\right)>0 .
$$

Furthermore, $\partial F / \partial(A / \rho)=\alpha\left(1-\tau_{1}\right)(1-s) s\left(\alpha+\tau_{1}\right)>0$. Applying the implicit function theorem shows

$$
\frac{\partial \tau_{1}}{\partial(A / \rho)}=-\frac{[\partial F / \partial(A / \rho)]}{\left(\partial F / \partial \tau_{1}\right)}<0
$$

F. Proof of of Theorem 10. Partial derivatives of (24) are

$$
\begin{aligned}
& \frac{\partial F}{\partial \tau_{1}}=-\left\{(1-s)\left(\alpha+\lambda \tau_{2}\right)\left[\alpha+s+(1-s) \lambda \tau_{2}\right]\right\} / N^{2}-1<0 \\
& \frac{\partial F}{\partial \tau_{2}}=\left\{(1-s)\left(\alpha+\tau_{1}\right) s\left(1-\tau_{1}\right)\right\} / N^{2}>0 \\
& \frac{\partial G}{\partial \tau_{1}}=\left\{(1-s)\left(\alpha+\lambda \tau_{2}\right) s\left(1-\tau_{2}\right)\right\} / N^{2}>0 \\
& \frac{\partial G}{\partial \tau_{2}}=-\left\{s\left(\alpha+\tau_{1}\right)\left[\alpha+(1-s) \lambda+s \tau_{1}\right]\right\} / N^{2}-1<0 \\
& \frac{\partial F}{\partial \lambda}=\left\{(1-s) s\left(1-\tau_{1}\right)\left(\alpha+\tau_{1}\right) \tau_{2}\right\} / N^{2}>0 \\
& \frac{\partial G}{\partial \lambda}=-\left\{(1-s) s\left(1-\tau_{2}\right)\left(\alpha+\tau_{1}\right) \tau_{2}\right\} / N^{2}+\frac{\alpha}{\lambda^{2}}, \quad \text { where } N \equiv \alpha+s \tau_{1}+(1-s) \lambda \tau_{2} .
\end{aligned}
$$

We first consider fighting intensity of group 1. Using the implicit function theorem and Cramer's rule

$$
\frac{\partial \tau_{1}}{\partial \lambda}=\frac{\operatorname{det} J_{1, \lambda}}{\operatorname{det} J}, \quad \operatorname{det} J=\frac{\partial F}{\partial \tau_{1}} \frac{\partial G}{\partial \tau_{2}}-\frac{\partial F}{\partial \tau_{2}} \frac{\partial G}{\partial \tau_{1}}, \quad \operatorname{det} J_{1, \lambda}=-\frac{\partial F}{\partial \lambda} \frac{\partial G}{\partial \tau_{2}}+\frac{\partial F}{\partial \tau_{2}} \frac{\partial G}{\partial \lambda} .
$$

From the proof of Theorem 7 we use $\operatorname{det} J>0$.

$$
\operatorname{det} J_{1, \lambda}=-\frac{(1-s) s\left(\alpha+\tau_{1}\right) \tau_{2}}{N^{2}} M_{2}+\frac{\alpha}{\lambda^{2}} \frac{\partial F}{\partial \tau_{2}}, \quad M_{2} \equiv\left(1-\tau_{1}\right) \frac{\partial G}{\partial \tau_{2}}+\left(1-\tau_{2}\right) \frac{\partial F}{\partial \tau_{2}} .
$$

Because $\partial F / \partial \tau_{2}>0$, it is sufficient to show that $M_{2}<0$ to prove positivity of $\operatorname{det} J_{1, \lambda}$.

After some algebra $M_{2}$ simplifies to $M_{2}=-\left(1-\tau_{1}\right)\left(\alpha+\tau_{1}\right) s / N^{3}-\left(1-\tau_{1}\right)<0$, and therewith $\operatorname{det} J_{1, \lambda} 1<0$ and $\partial \tau_{1} / \partial \lambda>0$.

Similarly,

$$
\frac{\partial \tau_{1}}{\partial \lambda}=\frac{\operatorname{det} J_{2, \lambda}}{\operatorname{det} J}, \quad \operatorname{det} J_{2, \lambda}=-\frac{\partial F}{\partial \tau_{1}} \frac{\partial G}{\partial \lambda}+\frac{\partial F}{\partial \lambda} \frac{\partial G}{\tau_{1}},
$$

and

$$
\operatorname{det} J_{2, \lambda}=\frac{(1-s) s\left(\alpha+\tau_{1}\right) \tau_{2}}{N^{2}} M_{3}-\frac{\alpha}{\lambda^{2}} \frac{\partial F}{\partial \tau_{1}}, \quad M_{3} \equiv\left(1-\tau_{1}\right) \frac{\partial G}{\partial \tau_{1}}+\left(1-\tau_{2}\right) \frac{\partial F}{\partial \tau_{1}} .
$$

$M_{3}$ simplifies to $-\left(1-\tau_{2}\right)(1-s)\left(\alpha+\lambda \tau_{2}\right) / N^{3}<0$. Hence, the whole first term is negative. The second term, $-\left(\alpha / \lambda^{2}\right)\left(\partial F / \partial \tau_{1}\right)$ is, however, positive. Moreover, for $\lambda \rightarrow 0$ the second term approaches infinity while the first term approaches a finite value. The second term, therefore, dominates for sufficiently small $\lambda$ implying $\partial \tau_{2} / \partial \lambda>0$. 


\section{References}

Acemoglu, D., Johnson, S. and Robinson, J.A., 2001, The colonial origins of comparative development: An empirical investigation, American Economic Review 91, 1369-1401.

Acemoglu, D., Robinson, J.A. and Verdier, T., 2003, Kleptocracy and Divide and Rule: A Model of Personal Rule, Journal of the European Economic Association 2, 162-192.

Alesina, A., Devleeschauwer, A., Easterly, W., Kurlat, S. and Wacziarg, R., 2003, Fractionalization, Journal of Economic Growth 8, 155-194.

Alesina, A. and La Ferrara, E., 2005, Ethnic diversity and economic performance, Journal of Economic Literature 43, 721-761.

Alexander, M. and Harding, M.C., 2005, Is poverty to blame for civil war? New evidence from non-linear fixed effect estimation, Discussion paper, Harvard.

Anderson, B., 1983, Imagined Communities, Reflections on the Origin and Spread of Nationalism, Verso Editions, London.

Barro, R.J. and Sala-i-Martin, X., 2004, Economic Growth, 2nd ed., MIT Press, Cambridge, MA.

Baron, R.A. and Byrne, D., 2004, Social Psychology, 10st ed., Pearson Education, Boston.

Barth, F., 1999, Introduction, in: Ethnic Groups and Boundaries, ed. by F. Barth, Little, Brown, and Company, Boston, MA.

Benhabib, J. Rustichini, A., 1996, Social conflict and growth, Journal of Economic Growth 1, 125-142.

Collier, P. and Hoeffler, A., 2004, Greed and grievance in civil war, Oxford Economic Papers 56, 663-595.

Collier, P. and Gunning, J.W., 1999, Explaining African economic performance, Journal of Economic Literature 37, 64-111.

Easterly, W. and Levine, R., 1997, Africa's growth tragedy: Policies and ethnic divisions, Quarterly Journal of Economics 111, 1203-1250.

Easterly, W., 2001a, The middle class consensus and economic development, Journal of Economic Growth 6, 317-335. Easterly, W., 2001b, Can institutions resolve ethnic conflict?, Economic Devlopment and Cultural Change 49, 687-706.

Easterly, W. and Levine, R., 2003, Tropics, germs, and crops: How endowments influence economic development, Journal of Monetary Economics 50, 3-39.

Eck, K., 2003, Collective Violence in 2002 and 2003, in: Harbom, L. (ed.), States in Armed Conflict, Uppsala University: Department of Peace and Conflict Research Report 70.

Fearon, J.D. and Laitin, D.D., 2003, . American Political Science Review, 97, 75-90.

Garfinkel, M.R., 1990, Arming as a strategic investment in a cooperative equilibrium, American Economic Review 80, 50-68.

Gonzalez, F.M., 2006, Effective property rights, conflict and growth, Journal of Economic Theory, forthcoming.

Grossman, H.I., 2001, The creation of effective property rights, American Economic Review 91, 347-352.

Grossman, H.I. and Kim, M., 1996, Predation and accumulation, Journal of Economic Growth 1, 333-350.

Hall, R.E. and Jones, C.I., 1999, Why do some countries produce so much more output per worker than others?, Quarterly Journal of Economics, 114, 83-116.

Hirshleifer, J., 1988, The analytics of continuing conflict, Synthese 76, 201-233.

Hirshleifer, J., 1991, The paradox of power, Economics and Politics 3, 177-200.

Hirshleifer, J., 1995, Anarchy and its breakdown, Journal of Political Economy 103, 26-52. 
Isham, J., Woolcock, M., Pritchett, L., and Busby, G., 2005, The varieties of resource experience: Natural resource export structures and the political economy of economic growth, World Bank Economic Review 19, 141-174.

Keefer, P. and Knack, S., 1997, Why don't poor countries catch up? A cross-national test of institutional explanation, Economic Inquiry 35, 590-602.

Knack, S. and Keefer, P., 1995, Institutions and economic performance: Cross- country tests using alternative measures, Economics and Politics 7, 207-227.

Konrad, K.A., 2002, Investment in the absence of property rights; the role of incumbency advantages, European Economic Review 46, 1521-1537.

Lane, P.R. and Tornell, A., 1996, Power, growth, and the voracity effect, Journal of Economic Growth 1, 213-241.

LeVine, R.A. and Campbell, D.T., 1972, Ethnocentrism: Theories of conflict, ethnic attitudes and group behavior, Wiley, New York.

Long, N.V. and Sorger, G., 2006, Insecure property rights and growth: The role of appropriation costs, wealth effects, and heterogeneity, Economic Theory 28, 513-529.

Lindner, I. and Strulik, H., 2004, Why not Africa? - Growth and welfare effects of secure property rights, Public Choice 120, 143-167,

Lindner, I. and Strulik, H., 2005, Social fractionalization, endogenous appropriation norms, and economic development, Economica, forthcoming.

Mkandawire, T., 2002, The terrible toll of post-colonial rebel movements in Africa: towards an explanation of the violence against the peasantry, Journal of Modern African Studies 40, 181-215.

Mauro, P., 1995, Corruption and growth, Quarterly Journal of Economics 110, 681-712.

McDermott, J., 1997, Exploitation and growth, Journal of Economic Growth 2, 251-278.

Mehlum, H., Moene, K., and Torvik, R., 2006, Institutions and the resource curse, Economic Journal 116, 1-20.

Montalvo, J.G. and Reynal-Querol, M., 2005, Ethnic polarization, potentail conflict, and civil wars, American Economic Review 95, 796-816.

Ogaki, M., Ostry, J.D. and Reinhart, C.M., 1996, Saving behavior in low- and middle-income developing economies, IMF Staff Papers 43, 38-71.

Rodrik, D., 1999, Where did all the growth go? External shocks, social conflict, and growth collapses, Journal of Economic Growth 4, 385-412.

Rodrik, D., Subramanian, A. and Trebbi, F., 2004, Institutions rule: The primacy of institutions over geography and integration in economic development, Journal of Economic Growth 9, 131-165.

Sherif, M., Harvey, O.J., White, B.J., Hood, W.R. and Sherif, W.C., 1961, Intergroup Cnflict and Co-operation: The Robber's Cave Experiment, University of Oklahoma Press, Norman, Oklahoma.

Tajfel, H. and Turner, J., 1979, An integrative theory of intergroup conflict, in G.W. Austin and S. Worchel (Eds.), The Social Psychology of Intergroup Relations, Monterey, CA: Brooks Cole.

Tornell, A., Lane, P.R., 1999, The voracity effect, American Economic Review 89, 22-46.

UN, 2005, Transnational Organized Crime in the West African Region, United Nations, New York. 